\title{
Drying Characteristics of Jackfruit and Snake Fruit using Freeze Dryer
}

\section{Joko Nugroho Wahyu Karyadi*, Siti Rahma, Ronal Sitindaon, Dionisia Gusda Primadita Putri and Dwi Ayuni}

Departement of Agricultural and Biosystems Engineering, Faculty of Agriculture Technology, Universitas Gadjah Mada, Jl. Flora No. 1 Bulaksumur, Yogyakarta 55281, Indonesia

\begin{abstract}
Jackfruit (Artocarpus heterophyllus Lam.) and snake fruit [Salacca zalacca (Gaert.) Voss] are tropical fruits that are rich in vitamins and minerals. Due to their specific aroma and unique taste, jackfruit and snake fruit have great potential to be processed into dried fruits and healthy snacks. In this work, jackfruit and snake fruit were freeze-dried using a self-designed laboratory-scale freeze dryer. The freeze dryer was constructed with a stainless-steel plate ( $3 \mathrm{~mm}$ thickness). The drying rates were determined with three different heating temperatures: 50,60 , and $70^{\circ} \mathrm{C}$. This study also investigated the effect of the freeze-drying process on the characteristics of dried fruit such as moisture content, texture, color, ascorbic acid content, and morphological of dried samples. Results showed that the heating temperatures were revealed to affect characteristics such as drying rate, final moisture content, texture, and ascorbic acid content. Increased drying rate and decreased drying time were observed with an increase in the dryer temperature. The sample resulted from $70^{\circ} \mathrm{C}$ of heating temperature exhibited the optimum results in terms of hardness and ascorbic content preservation. The first-order kinetic model was the best fit for the prediction of drying kinetics of all materials.
\end{abstract}

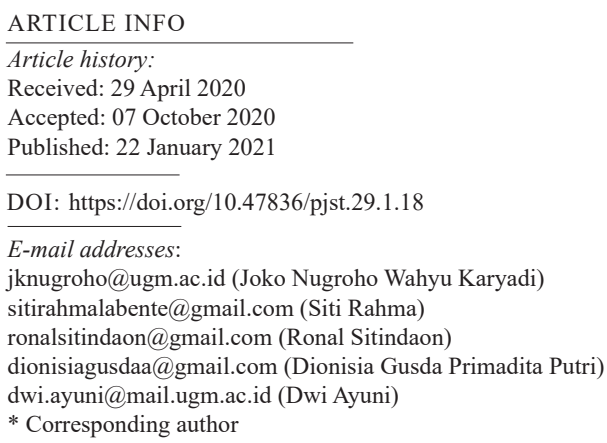

Keywords: Drying rate, freeze drying, jackfruit, physical and chemical characteristics, snake fruit

\section{INTRODUCTION}

Jackfruit (Artocarpus heterophyllus Lam.) and snake fruit (Salacca zalacca) may not yet be considered as well-known tropical fruits globally, but they are widely cultivated in Asia, including Indonesia (Palupi et al., 2019; Zumaidar \& Miftahuddin, 2018). 
Jackfruit and snake fruit were proven to be a great source of nutrition for human health (Ranasinghe et al., 2019; Suica-Bunghez et al., 2016). Regardless of all benefits offered, tropical fruits such as jackfruit and snake fruit are known as highly perishable and susceptive to deterioration due to its high respiration rate and water activity (Fundo et al., 2015). Extreme conditions such as high pressure and temperature can also affect the quality, like the changes in fruit firmness, color, and other physical quality traits (Liu et al., 2019). Especially for jackfruit, around 60\% portion of this fruit is inedible (Rana et al., 2018), so it is less profitable to sell whole fruit to the export market. Therefore, the marketing and transportation of these fruits remain a big challenge. They need to be processed to be able to have a long shelf life as well as easy to handle.

A fruit processing that can be done is drying (Fernandes et al., 2011; Soebiantoro et al., 2018). Among all drying methods, freeze-drying seems to be the superior method to remove the water as well as retain the nutrients and physicochemical characteristics of fruits (Kang et al., 2014; Turkiewicz et al., 2019). Freeze-drying is a process in which the moisture content inside the fruit is crystallized at a low temperature and subsequently sublimated from the solid-state directly into the vapor phase (Ciurzyńska \& Lenart, 2011). In general, The temperature and drying time can improve the reaction rates and affect the water activity of the product. Because of the water evaporation process, ascorbic acid content can be increased. The good quality of ascorbic acid can be retained by the freezedrying process (Prabhakar \& Mallika, 2014).

Several studies have focused on the evaluation of the freeze-drying process to the widely known tropical fruits such as soursop (Ceballos et al., 2012) and mango (Rahman et al., 2015). However, there are still very few studies focused on the freeze-drying of jackfruit and snake fruit. The processing of jackfruit and snake fruit using a freeze-drying method can open up opportunities for these fruits to be produced into healthy snacks that are easy to handle and transported to the export market. Therefore, this study was aimed to evaluate the performance of mini freeze-dryer for jackfruit and snake fruit. The effect of the heating temperatures on the characteristics of the freeze-dried fruits like moisture content, colour, texture, and ascorbic acid contents was also investigated.

\section{MATERIALS AND METHODS}

\section{Materials}

Ripen jackfruit and snake fruit (cultivar name: Salak Pondoh) were purchased from a local market of Sleman Regency, Yogyakarta, Indonesia. One distributor was picked to maintain the same variety and quality of fruits used. Ripen jackfruit was shown by its bright yellow colour of the flesh and its distinctive aroma. Selected jackfruit had an average weight of $10-15 \mathrm{~kg}$. Meanwhile, ripen snake fruit had a yellowish-brown skin colour, with an average weight of $60-80 \mathrm{~g}$. Fruits were processed on the same day they were bought, 
to avoid any undesired changes in fruit quality. The average total soluble solid (TSS) of fresh jackfruit and snake fruit ranged from 18 to 30 and 16 to $19^{\circ}$ Brix, respectively. The approximate moisture content of fresh jackfruit and snake fruit were $77.38 \pm 4.97 \% \mathrm{wb}$ and $81.61 \pm 1.01 \% \mathrm{wb}$, respectively. All the fruits were washed and peeled. Fruits were cut into uniform shapes of $2 \times 5 \mathrm{~cm}^{2}$ with an average thickness of $5 \mathrm{~mm}$, then put on a tray to be dried using freeze-drying.

\section{Experimental Freeze Dryer}

Figure 1 shows the laboratory freeze-drying system used in this work. The freeze dryer had $0.7 \times 0.5 \times 1 \mathrm{~m}^{3}$ of the total dimension as well as $0.4 \mathrm{~m}$ diameter $\mathrm{x} 0.6 \mathrm{~m}$ length of the drying chamber. There were three main systems in the freeze dryer, namely: the vacuum chamber system, the cooling system, and the heating system. The vacuum chambers, doors, and steam traps were made using stainless steel with $3 \mathrm{~mm}$ thickness. The vacuum pump used in this study was a two-stage vacuum pump with $1 \mathrm{HP}$ (horsepower) power (VALUE VE2100N, Zhejiang, China). The cooling system was constructed using $1 / 4 \mathrm{HP}$ compressor refrigerant compressor (Fuji - Kobe SR91, Fuji Electric, Tokyo, Japan), to cool the vacuum chambers and water traps. Whereas the heating system used four rectangular heater mats $\left(40 \times 20 \mathrm{~cm}^{2}\right)$ with the power of 2000 watt for each, arranged in series to 500 watts. The heater mats were installed above and below the material rack.

Experiments were performed with a total pressure of $75.5 \mathrm{cmHg}$ vacuum, as well as the freezing time and the total drying time of 6 hours and 36 hours, respectively. The freezedrying process was run with the heating temperature set for 50,60 , and $70^{\circ} \mathrm{C}$. The heating

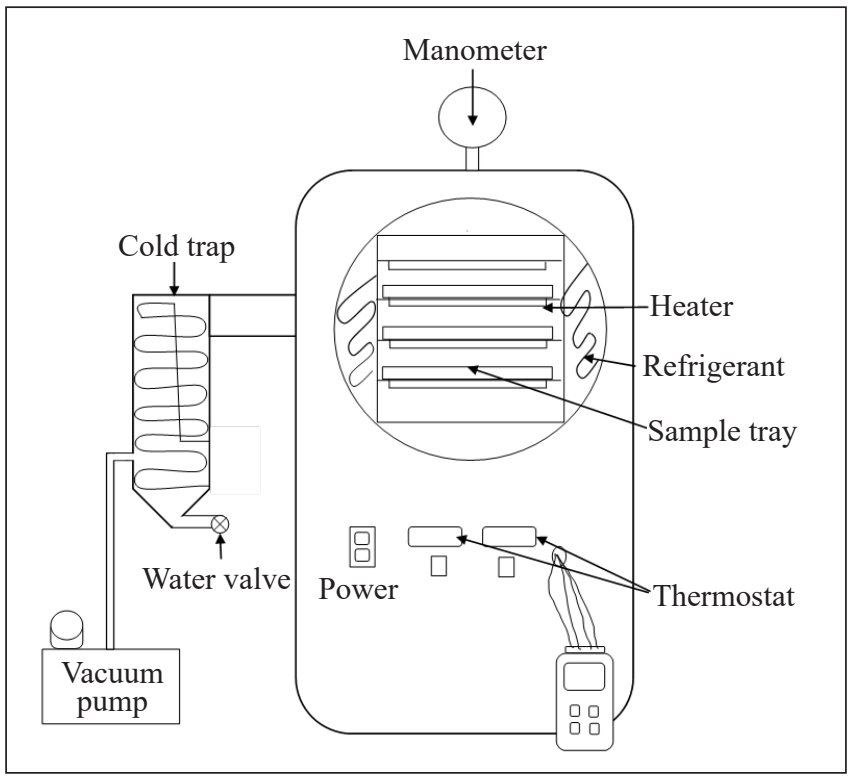

Figure 1. Laboratory freeze-drying system 
temperature was set to improve the secondary drying, therefore the evaporation process of bound water can be done as quickly as possible. Based on the results of the preliminary test, the use of heating temperatures above $70^{\circ} \mathrm{C}$ caused non-enzymatic browning, while temperatures below $50^{\circ} \mathrm{C}$ were time-consuming and were not optimal to dry samples.

A pressure gauge (Wiebrock EN 837-1, Wiebrock, Herford, Nort Rhine-Westphalia) and thermometer (Lutron TM-946, Lutron Electronic Enterprise Co., LTD, Taipei, Taiwan, with the standard error of $2.2^{\circ} \mathrm{C}$ ) were used to measure and monitor the pressure and the temperatures during the drying, respectively. The products obtained from the freeze-drying process were weighed, and their physical properties were determined. The freeze-dried fruits were stored in an aluminum bag until they were used for the next analyses.

\section{Moisture Content}

The moisture content of the samples was measured using the methods explained by Park (2008), based on the Official Methods of Analysis of AOAC International with slight modification. The initial samples were weighed for $2 \mathrm{~g}$ and were dried in an oven (Memmert $\mathrm{UM}-400$, Memmert GmbH $+\mathrm{Co} . \mathrm{KG}$, Schwabach, Germany) at $105^{\circ} \mathrm{C}$ for 24 hours to get a bone dry sample. The weight reduction from the initial to the bone dry was considered as the water amount contained in the sample. The calculation to determine the moisture content was presented by Equation 1.

$$
M=\frac{W_{0}-W_{1}}{W_{1}}
$$

where $M$ was the moisture content (g/g dry solid), $W_{0}$ was the initial mass sample at the pre-determined time during drying $(\mathrm{g})$, and $W_{l}$ was a dry matter of sample after 24 hours oven drying $(\mathrm{g})$.

To collect the drying kinetic data, the moisture ratio of the samples measured for 12 , 18,24 , and finally 36 hours of drying. Since the equilibrium moisture content $M e$ was very low and imperceptible, the moisture ratio $M R$ was simplified (Liu et al., 2016), as presented by Equation 2.

$$
M R=\frac{M-M_{e}}{M_{0}-M_{e}} \approx \frac{M}{M_{0}}
$$

where $M$ and $M_{0}$ were the moisture content at pre-determined time and the initial moisture content, respectively (g/g dry solid).

The moisture ratio during drying was then described by a first-order kinetic model. The first-order model is the most common and well-understood model used for exponential modelling in engineering investigations (Singh et al., 2018). The model was presented by Equation 3 (Orikasa et al., 2018). 


$$
M R=e^{-k t}
$$

where $M R$ was the moisture ratio (-), $k$ was the drying rate constant $\left(\mathrm{h}^{-1}\right)$ and $t$ was drying time (h).

The drying constant, $k$, was estimated by fitting the obtained moisture content data to Equation 3 using the least-squares method. To evaluate the goodness of fit, the determination coefficient $\left(\mathrm{R}^{2}\right)$ was calculated using Equation 4 (Saberian et al., 2014).

$$
R^{2}=1-\frac{\sum_{i=1}^{N}\left(M R_{\text {pre }, i}-M R_{\text {exp }, i}\right)^{2}}{\sum_{i=1}^{N}\left(M R_{\text {pre }}-M R_{\text {exp }, i}\right)^{2}}
$$

where $N$ was the number of observations, $m$ was the number of constants, $M R_{\text {pre }, i}$ and $M R_{\text {exp }, i}$ were the $i$-th predicted and experimental moisture ratio, respectively.

\section{Shrinkage}

Shrinkage (\%) was calculated using the formula presented by Equation 5

$$
\text { Shrinkage }=\frac{\left(D_{0}-D_{1}\right)}{D_{0}} \times 100 \%
$$

where $D_{0}$ was dimension (length, width, or thickness) before drying, and $D_{l}$ was dimension after drying.

\section{Color Analysis}

The color analysis was performed using Color Meter (Color Meter TES-135A, TES Electrical Electronic Corp., Taipei, Taiwan). The lightness $\left(L^{*}\right)$, redness/greenness $\left(a^{*}\right)$, and yellowness/blueness $\left(b^{*}\right)$ were evaluated. These parameters were used to calculate the color changes $(\Delta E)$ (Ceballos et al., 2012), which was presented by Equation 6 .

$$
\Delta E=\sqrt{\left(L *-L_{0}\right)^{2}+\left(a *-a_{0}\right)^{2}+\left(b *-b_{0}\right)^{2}}
$$

where $L_{0}, a_{0}$, and $b_{0}$ were the lightness, redness/greenness, and yellowness/blueness of the fresh sample, respectively.

\section{Texture Analysis}

Texture analysis was carried out by measuring the deformation force with a Texture Analyser (Brookfield CT3 Texture Analyser, Middleboro, MA, USA), using a cylindrical probe TA39 $($ diameter $=2 \mathrm{~mm})$. Freeze-dried fruit was placed on the texture analyser 
plate and compressed at a rate of $1 \mathrm{~mm} / \mathrm{s}$ until $20 \mathrm{~mm}$ penetration was achieved using one compression cycle. The force $(\mathrm{N})$ required to deform the sample was defined as hardness.

\section{Ascorbic Acid Content}

The ascorbic acid content was determined using a 2.6D method from AOAC (Nielsen, 2017). Especially for freeze-dried samples, 200 - 300 g samples were crushed using a Waring blender to get slurry. About $10 \mathrm{~g}$ of the slurry was dissolved in $100 \mathrm{ml}$ of distilled water. After that, the dilution was put into a centrifuge to separate the filtrate. $100 \mathrm{ml}$ filtrate of fresh and freeze-dried samples were homogenized with $100 \mathrm{ml}$ of HPO3-HOAc and then filtered through filter paper. About $10 \mathrm{ml}$ of filtrate was titrated with 2,6-dichloroindophenol (DCPIP) indicator. The ascorbic acid contents measured were presented in $\mathrm{mg} / 100 \mathrm{~g}$ in dry matter (DM) of the samples.

\section{Scanning Electron Microscopy (SEM)}

The magnified image of the cross-sectional morphology of freeze-dried fruits was observed using Scanning electron microscopy (SEM; JSM 6510LA JEOL Ltd., Tokyo, Japan). The sample was coated with Platinum/Palladium metal using an Auto Fine Coater before placed over the SEM sample holder using double-sided tape.

\section{Statistical Analysis}

Statistical analysis was performed using IBM SPSS Statistics 23 software (SPSS Inc., Chicago, IL). The characteristics of freeze-dried fruits were introduced to variance analysis (ANOVA) with a $95 \%$ significance level. When the conditions were achieved, the Duncan test was used to test the homogeneity of variances among samples.

\section{RESULTS AND DISCUSSION}

\section{Drying Temperature and Pressure}

Figure 2 shows the temperature and pressure during the freeze-drying process. In general, it can be seen from all graphs that for all heating temperatures, the product temperature reached $-5^{\circ} \mathrm{C}$ during the freezing stage. The freezing rates should be kept low to allow simultaneous dehydration and inhibit the increase of vapor flux during the next stage (Marques \& Freire, 2005). According to Shukla (2011), during the primary stage of drying, the increased temperature warms the sample, yet the low pressure below 0.06 atm $(71.44$ $\mathrm{cmHg}$ vacuum) prevents the liquid forming. As a consequence, the ice crystal became vapor, and the sublimation started to occur. Several other studies used even lower pressure and temperature during their freeze-drying process. Valentina et al. (2016) freeze-dried several types of food with the pressure and freezing temperature were set at 60 millitorrs $(75.94$ 


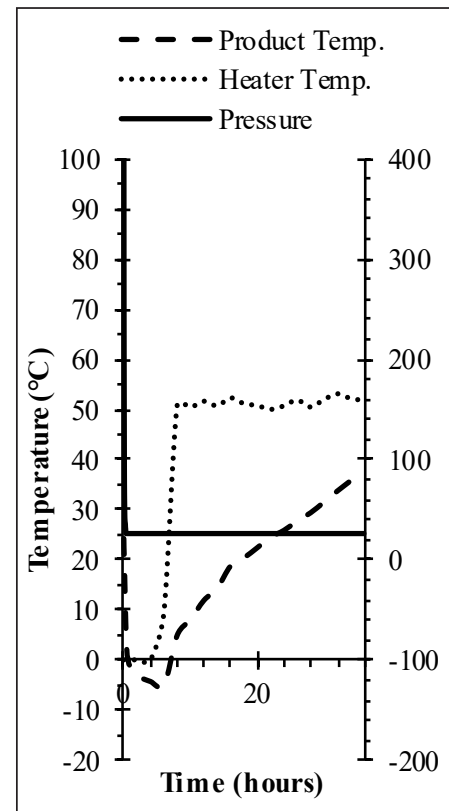

(a)

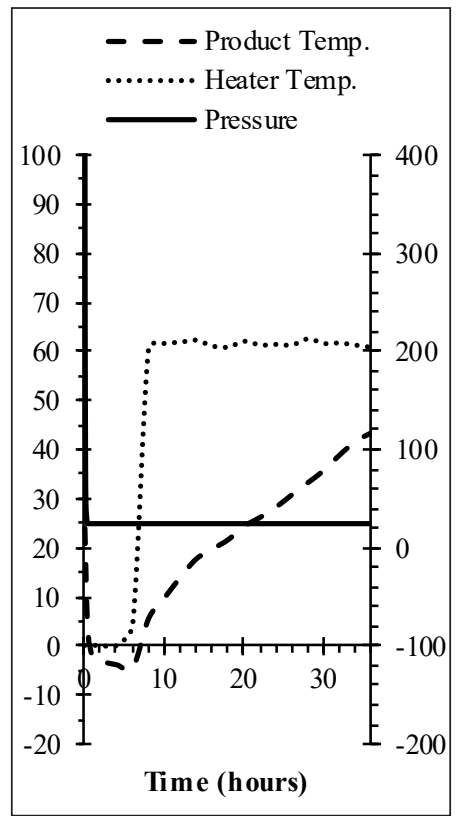

(b)

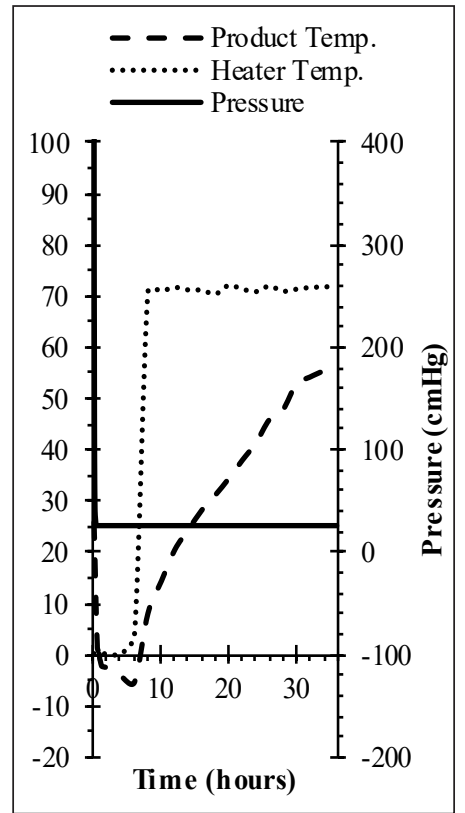

(c)

Figure 2. Temperature and pressure during freeze drying of jackfruit for different heating temperatures setting of (a) 50 , (b) 60 , and (c) $70^{\circ} \mathrm{C}$

$\mathrm{cm} \mathrm{Hg}$ vacuum) and $-40^{\circ} \mathrm{C}$, respectively. According to Figure 2, during the second stage of drying, the final product temperatures were varied, depending on the heating temperature applied. The product temperature after the drying process ranged from $35-55^{\circ} \mathrm{C}$. This result was similar to the study of tropical fruits freeze-drying done by Marques et al. (2006) which reached the product final temperature of $38^{\circ} \mathrm{C}$.

\section{Moisture Content}

The moisture content ratio of the jackfruit of 0.1 was fitted to the first-order kinetic model (Equation 3), shown in Figure 3, to evaluate the drying process in this study. The calculated results (shown by the solid lines) seem to agree-with the measured results $\left(\mathrm{R}^{2}=0.99\right)$, indicating the suitability of the model to explain the degradation of moisture ratio during freeze-drying. From the graph, it can be seen that the drying rate decreased linearly after the first few hours of drying. The drying rate constants calculated for temperatures of 50 , 60 , and $70^{\circ} \mathrm{C}$ were $0.1296,0.1623$, and $0.1957 \% / \mathrm{h}$, respectively. The results show that different increasing heating temperatures increased the drying rate of jackfruit in the first falling rate period. These results confirm that higher drying temperature would produce greater heat transfer, therefore induced moisture evaporation (Sanwiriya \& Suleiman, 2019).

The final moisture content of dried jackfruit by the heating temperature of $70^{\circ} \mathrm{C}$ was $4.29 \% \mathrm{db}$. This result was similar to that obtained by Yi et al. (2016), who applied the 


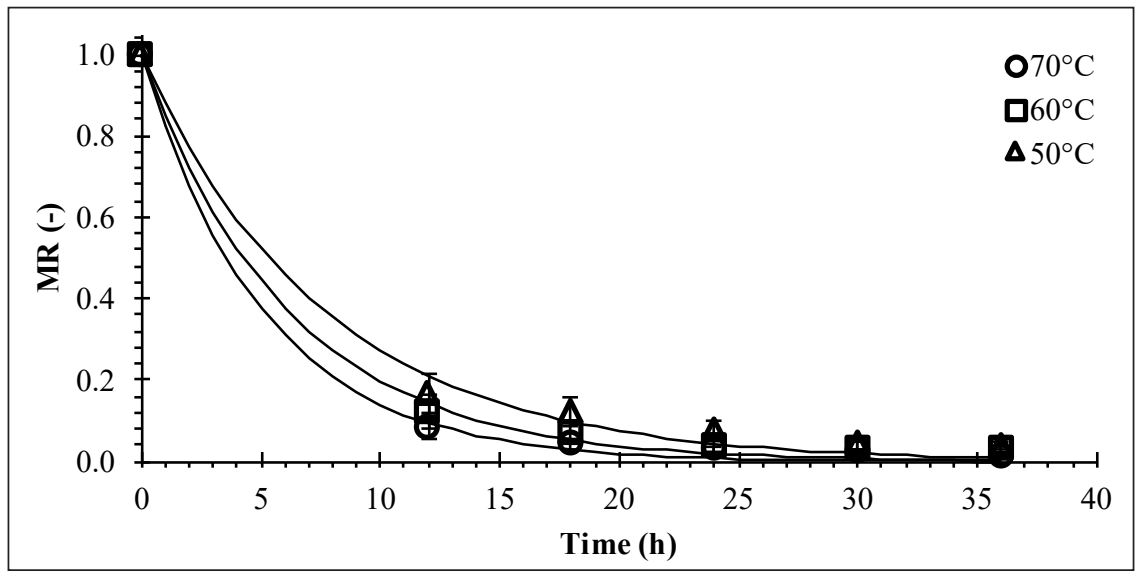

Figure 3. Plot of Moisture Ratio (MR) at three different heating temperatures for freeze-drying process of jackfruit

freeze-drying to dry jackfruit, with the pressure of $0.1 \mathrm{kPa}(75.93 \mathrm{cmHg}$ vacuum) and the secondary drying temperature of $25^{\circ} \mathrm{C}$, and got the final moisture content of $4.9 \% \mathrm{db}$. Meanwhile, the final moisture contents of dried jackfruit by the heating temperature of 50 and $60^{\circ} \mathrm{C}$ were 14.04 and $11.33 \% \mathrm{db}$, respectively. Meanwhile, the final moisture content of dried snake fruit was $10.52,4.59$, and $2.18 \% \mathrm{db}$ for the heating temperature of 50,60 , and $70^{\circ} \mathrm{C}$, respectively.

The higher the heating temperature, the lower the final moisture contents obtained for each fruit sample $(p<0.05)$. Lower moisture content may provide to the crispness of freezedried chips. The moisture content should be lowered to below $4 \%$ to have a good shelf life and quality. Moreover, the conventional freeze-drying permits reduction of moisture to less than $2 \%$ (Prabhakar \& Mallika, 2014). Therefore, from the results obtained, $70^{\circ} \mathrm{C}$ was chosen as the best temperature applied to get the optimum final moisture content.

\section{Characteristics of Freeze-dried Jackfruit and Snake Fruit}

Table 1 shows the characteristics of freeze-dried jackfruit and snake fruit. Ratti (2001) who reviewed the comparison of hot air and freeze-drying of high-value foods, stated that shrinkage during freeze-drying was ranged from 5 to $15 \%$, while during air-drying shrinkage was around $80 \%$. However, from this study, the shrinkages obtained during freeze-drying were quite excessive $(20-40 \%)$, with the effect of heating temperature not giving any tendency of significant difference to the results $(p>0.05)$. The shrinkage could be happen due to the short freezing time in the process, which was 6 hours. One study reported that a longer freezing time could decrease drying shrinkage (Ciurzyńska \& Lenart, 2011). 


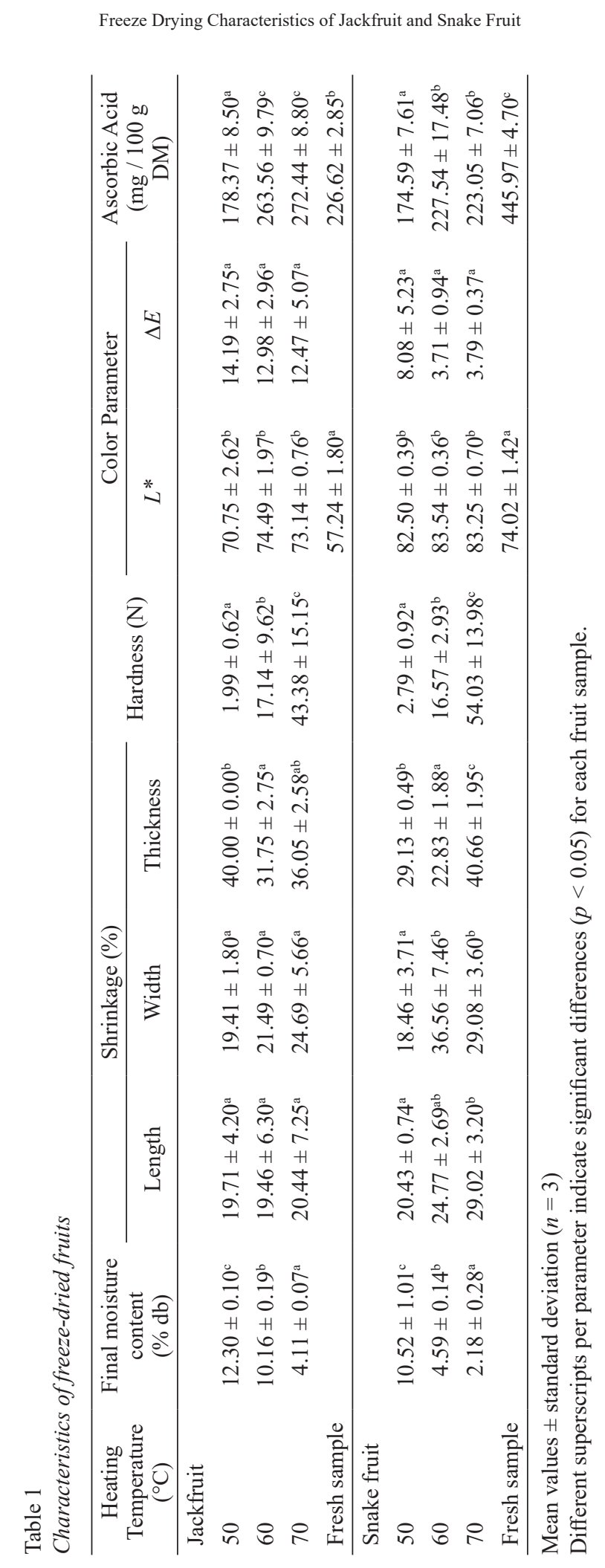

Pertanika J. Sci. \& Technol. 29 (1): 317 - 330 (2021) 
According to Table 1, the higher temperature would result in a more rigid texture, marked by the higher hardness results $(\mathrm{p}<0.05)$. The lower final moisture obtained at low temperature could reduce the glass transition point, leading to a stronger matrix of the fruits (Mounir et al., 2012). The hardness results of the $70^{\circ} \mathrm{C}$ heating temperature for snake fruit and jackfruit were $54.03 \pm 13.98$ and $43.38 \pm 15.15 \mathrm{~N}$, respectively. The results obtained were higher than those done by previous studies of jackfruit freeze-drying (Yi et al., 2016).

Both snake fruit and jackfruit showed a significant increase of $L^{*}$ value, showed rising brightness after drying $(\mathrm{p}<0.05)$. These results confirmed one of the merits of freeze-drying to preserve the color of products. Similar results were also obtained by previous studies done for soursop (Ceballos et al., 2012), apple, banana, potato, and carrot (Krokida et al., 2001). There was no difference in $\Delta E$ data among different heat temperatures $(\mathrm{p}>0.05)$.

For the analysis of ascorbic acid content, the freeze-dried fruits from $50^{\circ} \mathrm{C}$ of heating temperature were significantly lower in ascorbic acid content than other variations $(\mathrm{p}<$ 0.05). Besides oxygen and temperature, moisture content also affects the degradation of ascorbic acid. Final moisture content that was still high in products would generate high water activity, leading to a decrease of ascorbic acid content (Lee \& Kader, 2000). A previous study had proven that freeze-drying was more effective in preserving ascorbic content in products since its degradation was approximately $40 \%$ lower than that in air drying (Orak et al., 2012).

\section{Scanning Electron Microscopy}

Good appearance, adequate rehydration, and crisp texture are the characteristic of freezedrying products. Figure 4 shows the cross-sectional of SEM micrographs of the freezedried fruits operated at 100 $\times$ magnification. Figure 4a, c, and e correspond to the heating temperatures of 50,60 , and $70^{\circ} \mathrm{C}$ for jackfruit, respectively. Figure $4 \mathrm{~b}, \mathrm{~d}$, and $\mathrm{f}$ correspond to the heating temperatures of 50,60 , and $70^{\circ} \mathrm{C}$ for snake fruit, respectively.

In general, there was a qualitative difference in pore size among different heat temperatures. Commonly in freeze-drying, the material is in the glassy state, and the ice sublimation creates pores (Ismail et al., 2016; Rahman, 2001). Therefore, the final product of freeze-drying is very porous (as can be seen in $70^{\circ} \mathrm{C}$ ). On the other hand, the SEM results for the temperature of 50 and $60^{\circ} \mathrm{C}$ seemed dense and withered. The minimum appearances of the pores suggest the products still in the rubbery state, which confirms the low hardness results discussed above. High porosity helps to maintain the structure without the deformations, allowing a fast rehydration process due to that water easily reoccupies the empty spaces (Pieniazek \& Messina, 2017). 

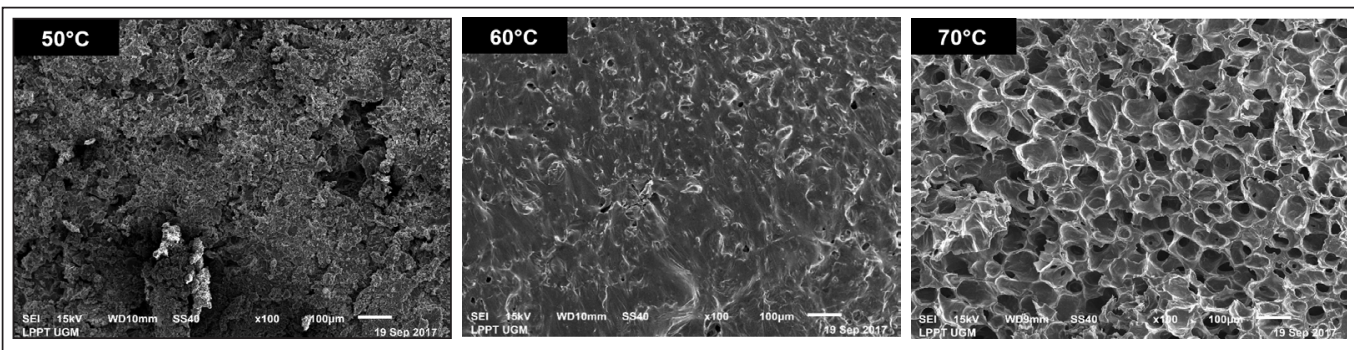

(a)

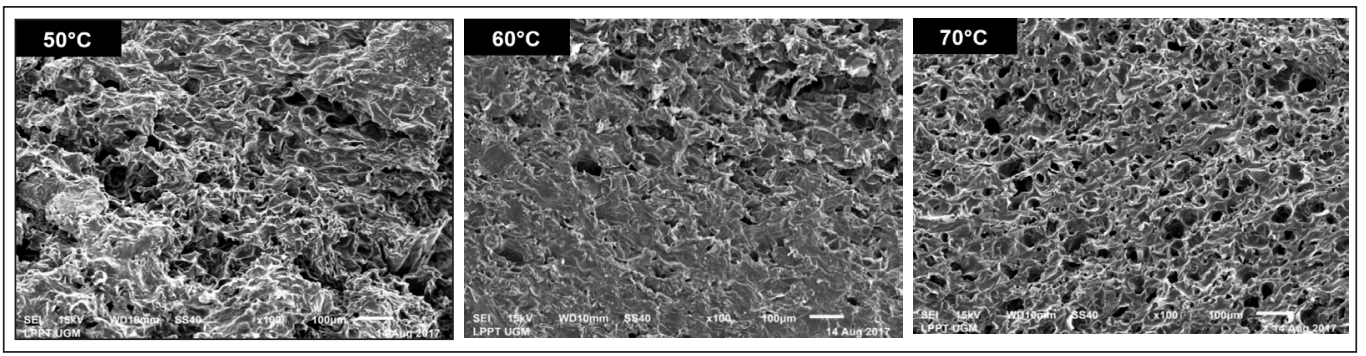

(b)

Figure 4. 100 $\times$ SEM micrographs of freeze-dried fruits for (a) jackfruit and (b) snake fruit

\section{CONCLUSIONS}

This study investigated the effect of temperature on the characteristic changes for snake fruit and jackfruit during freeze-drying. A mathematical model based on first-order kinetic function was developed to simulate the moisture ratio of fruits undergoing freeze-drying. The simulation results showed that first-order kinetic could predict freeze-drying kinetics of jackfruit with adequate accuracy. The highest drying rate was reported from the heating temperature of $70^{\circ} \mathrm{C}$, which was $0.1957 \% / \mathrm{h}$. The lowest moisture content of freezedried jackfruit and snake fruit were $4.11 \pm 0.07$ and $2.18 \pm 0.28 \%$, respectively. From the experiment carried out, it can be adequately stated that freeze-drying may be a suitable method for processing jackfruits and snake fruit, based on its ability to retain the color, aroma, and nutritional value after the drying.

\section{ACKNOWLEDGEMENT}

We thank Prof. Bambang Purwantana for his supervision during the design and construction of freeze-dryer. This research was funded by the Ministry of Research and Technology of Indonesia, through a program named "Excellent Researches of the University" in 2017 to 2019 . 


\section{REFERENCES}

Ceballos, A., Giraldo, G. I., \& Orrego, C. E. (2012). Effect of freezing rate on quality parameters of freeze dried soursop fruit pulp. Journal of Food Engineering, 111, 360-365. doi: https://doi.org/10.1016/j. jfoodeng.2012.02.010

Ciurzyńska, A., \& Lenart, A. (2011). Freeze-drying application in food processing and biotechnology - A review. Polish Journal of Food and Nutrition Sciences, 61(3), 165-171. doi: https://doi.org/10.2478/ v10222-011-0017-5

Fernandes, F. A. N., Rodrigues, S., Law, C. L., \& Mujumdar, A. S. (2011). Drying of exotic tropical fruits: A comprehensive review. Food and Bioprocess Technology, 4(2), 163-185. doi: https://doi.org/10.1007/ s11947-010-0323-7

Fundo, J. F., Amaro, A. L., Madureira, A. R., Carvalho, A., Feio, G., Silva, C. L. M., \& Quintas, M. A. C. (2015). Fresh-cut melon quality during storage: An NMR study of water transverse relaxation time. Journal of Food Engineering, 167, 71-76. doi: https://doi.org/10.1016/j.jfoodeng.2015.03.028

Ismail, M. H., Law, C. L., \& Hii, C. L. (2016). Transparency phenomena of flat-rice noodles (kuew teow) at drying at soaking variation. International Food Research Journal, 23(December), S195-S202.

Kang, O. L., Yong, P. F., Ma'aruf, A. G., Osman, H., \& Nazaruddin, R. (2014). Physicochemical and antioxidant studies on oven-dried, freeze-dried and spray-dried agaro-oligosaccharide powders. International Food Research Journal, 21(6), 2363-2367.

Krokida, M. K., Maroulis, Z. B., \& Saravacos, G. D. (2001). The effect of the method of drying on the colour of dehydrated products. International Journal of Food Science and Technology, 36(1), 53-59. doi: https:// doi.org/10.1046/j.1365-2621.2001.00426.x

Lee, S. K., \& Kader, A. A. (2000). Preharvest and postharvest factors influencing vitamin C content of horticultural crops. Postharvest Biology and Technology, 20(3), 207-220. doi: https://doi.org/10.1016/ S0925-5214(00)00133-2

Liu, B., Wang, K., Shu, X., Liang, J., Fan, X., \& Sun, L. (2019). Changes in fruit firmness, quality traits and cell wall constituents of two highbush blueberries (Vaccinium corymbosum L.) during postharvest cold storage. Scientia Horticulturae, 246, 557-562. doi: https://doi.org/10.1016/j.scienta.2018.11.042

Liu, Y. H., Li, X. F., Zhu, W. X., Luo, L., Duan, X., \& Yin, Y. (2016). Drying characteristics, kinetics model and effective moisture diffusivity of vacuum far-infrared dried Rehmanniae. International Journal of Agricultural and Biological Engineering, 9(5), 208-217. doi: https://doi.org/10.3965/j.ijabe.20160905.2082

Marques, L. G., \& Freire, J. T. (2005). Analysis of freeze-drying of tropical fruits. Drying Technology, 23, 2169-2184. doi: https://doi.org/10.1080/07373930500212438

Marques, L. G., Silveira, A. M., \& Freire, J. T. (2006). Freeze-drying characteristics of tropical fruits. Drying Technology, 24(4), 457-463. doi: https://doi.org/10.1080/07373930600611919

Mounir, S., Allaf, T., Mujumdar, A. S., \& Allaf, K. (2012). Swell drying: Coupling instant controlled pressure drop DIC to standard convection drying processes to intensify transfer phenomena and improve quality - An overview. Drying Technology, 30, 1508-1531. doi: https://doi.org/10.1080/07373937.2012.693145 
Nielsen, S. S. (2017). Vitamin C determination by indophenol method. In Food Analysis Laboratory Manual (pp. 143-146). Cham, Switzerland: Springer International Publishing. doi: https://doi.org/10.1007/9783-319-44127-6

Orak, H. H., Aktas, T., Yagar, H., Isbilir, S. S., Ekinci, N., \& Sahin, F. H. (2012). Effects of hot air and freeze drying methods on antioxidant activity, colour and some nutritional characteristics of strawberry tree (Arbutus unedo L) fruit. Food Science and Technology International, 18(4), 391-402. doi: https://doi. org/10.1177/1082013211428213

Orikasa, T., Ono, N., Watanabe, T., Ando, Y., Shiina, T., \& Koide, S. (2018). Impact of blanching pretreatment on the drying rate and energy consumption during far-infrared drying of paprika (Capsicum annuum L.). Food Quality and Safety, 2(2), 97-103. doi: https://doi.org/10.1093/fqsafe/fyy006

Palupi, D., Rahayu, S. S. B., \& Daryono, B. S. (2019). Genetic diversity in jackfruit (Artocarpus Heterophyllus Lam.) based on molecular characters in Indonesia. Sabrao Journal of Breeding and Genetics, 51(1), 57-67.

Park, Y. (2008). Moisture and water activity. In L. M. L. Nollet \& F. Toldrá (Eds.), Handbook of processed meats and poultry analysis (pp. 35-67). London, UK: CRC Press. doi: https://doi.org/10.1201/9781420045338. ch3

Pieniazek, F., \& Messina, V. (2017). Texture and color analysis of freeze-dried potato (cv. Spunta) using instrumental and image analysis techniques. International Journal of Food Properties, 20(6), 1422-1431. doi: https://doi.org/10.1080/10942912.2016.1211143

Prabhakar, K., \& Mallika, E. N. (2014). Dried foods. In C. A. Batt \& M. L. Tortorello (Eds.), Encyclopedia of food microbiology: Second edition (Vol. 1, pp. 574-576). San Diego, USA: Academic Press. doi: https:// doi.org/10.1016/B978-0-12-384730-0.00085-9

Rahman, M. M., Das, R., Hoque, M. M., \& Zzaman, W. (2015). Effect of freeze drying on antioxidant activity and phenolic contents of mango (Mangifera indica). International Food Research Journal, 22(2), 613-617.

Rahman, M. S. (2001). Toward prediction of porosity in foods during drying: A brief review. Drying Technology, 19(1), 1-13. doi: https://doi.org/10.1081/DRT-100001349

Rana, S. S., Pradhan, R. C., \& Mishra, S. (2018). Optimization of chemical treatment on fresh cut tender jackfruit slices for prevention of browning by using response surface methodology. International Food Research Journal, 25(1), 196-203.

Ranasinghe, R. A. S. N., Maduwanthi, S. D. T., \& Marapana, R. A. U. J. (2019). Nutritional and health benefits of jackfruit (Artocarpus heterophyllus Lam.): A review. International Journal of Food Science, 2019, 1-12. doi: https://doi.org/10.1155/2019/4327183

Ratti, C. (2001). Hot air and freeze-drying of high-value foods: A review. Journal of Food Engineering, 49, 311-319. doi: https://doi.org/10.1016/S0260-8774(00)00228-4

Saberian, H., Amooi, M., \& Hamidi-Esfahani, Z. (2014). Modeling of vacuum drying of loquat fruit. Nutrition and Food Science, 44(1), 24-31. doi: https://doi.org/10.1108/NFS-08-2012-0087

Sanwiriya, P., \& Suleiman, N. (2019). The effects of drying method and temperature on the nutritional quality of watermelon rinds. International Food Research Journal, 26(3), 953-958. 
Shukla, S. (2011). Freeze drying process: A review. International Journal of Pharmaceutical Sciences and Research, 2(12), 3061-3068.

Singh, A. P., Siddiqui, J., \& Diosady, L. L. (2018). Characterizing the pH-dependent release kinetics of food-grade spray drying encapsulated iron microcapsules for food fortification. Food and Bioprocess Technology, 11(2), 435-446. doi: https://doi.org/10.1007/s11947-017-2022-0

Soebiantoro, F. A., Tarigan, E., Hwa, L., Halim, V. P., \& Sapei, L. (2018). Drying characteristics of Curcuma longa using solar dryer. Pertanika Journal of Science and Technology, 26(3), 1265-1274.

Suica-Bunghez, I. R., Teodorescu, S., Dulama, I. D., Voinea, O. C., Imionescu, S., \& Ion, R. M. (2016). Antioxidant activity and phytochemical compounds of snake fruit (Salacca Zalacca). IOP Conference Series: Materials Science and Engineering, 133(1), 1-18. doi: https://doi.org/10.1088/1757899X/133/1/012051

Turkiewicz, I. P., Wojdyło, A., Lech, K., Tkacz, K., \& Nowicka, P. (2019). Influence of different drying methods on the quality of Japanese quince fruit. LWT - Food Science and Technology, 114, 1-8. doi: https://doi. org/10.1016/j.lwt.2019.108416

Valentina, V., Pratiwi, R. A., Hsiao, P. Y., Tseng, H. T., Hsieh, J. F., \& Chen, C. C. (2016). Sensorial characterization of foods before and after freeze-drying. Austin Food Sciences, 1(6), 1-5.

Yi, J., Wang, P., Bi, J., Liu, X., Wu, X., \& Zhong, Y. (2016). Developing novel combination drying method for jackfruit bulb chips: Instant controlled pressure drop (DIC)-assisted freeze drying. Food and Bioprocess Technology, 9(3), 452-462. doi: https://doi.org/10.1007/s11947-015-1643-4

Zumaidar, \& Miftahuddin. (2018). Species distribution of genus Salacca. Journal of Physics: Conference Series, 1116(2018), 1-8. doi: https://doi.org/10.1088/1742-6596/1116/5/052083 